\title{
Urban Expansion and Vegetation Cover Change in and Around Jimma Town Since 1990
}

\author{
Gammachu Fufa $^{1} \quad$ Mohammedreha Abajihad $^{1} \quad$ Amare Amsalu $^{2} \quad$ Mesfin Garsem $^{1}$ \\ Guddina Fayisa ${ }^{3}$ \\ 1. Jimma University College of Agriculture and Veterinary Medicine, Department of Natural Resource \\ Management \\ 2.Bonga University, Department of Natural Resource Management \\ 3.Addis Ababa University, College of Natural and Computational Sciences, Ethiopia
}

\begin{abstract}
Urbanization is the renovation of rural society into an urban society as a result of socio-economic and political growth leading to foundation and expansion of urban agglomerations along with changing land use patterns. The main aims of this study was Investigating the extent of vegetation loss through urban expansion in and around Jimma Town over a 30 period of 6 years interval by using Geographic Information System (GIS) and Remote Sensing (RS) techniques. To achieve this objectives, Data was obtained from earth explorer (USGS) 6 years interval from1990 to 2020 of the study area. Downloaded image were extracted and each layer stacked together using the digital image-processing software ENVI 5.2. The Processed images were classified using supervised classification Algorithms into 5 hierarchical classes; Built-up area, Vegetation, Agricultural land, Grass land, and wetlands based on a modified classification scheme. Change analysis was also undertaken by applying postclassification change detection procedures. Accuracy of the image classification was assessed using error matrix, overall accuracy and kappa coefficient. The change analysis result revealed that the LULC have shown both positive and negative significant changes. Built-up were the top LULC that experienced positive change; whereas grass land, vegetation, agricultural land and wetlands have substantially declined. An important implication of the observed changes is that rapid urban expansion, compounded by poor urban planning is leading to enormous losses of key ecosystems such as wetlands and natural vegetation. The consequence of this rapid ecological degradation could potentially impact ecological functioning and environmental sustainability in and around Jimma city. Therefore, critical system thinking is required to address these complex problems in the study area and areas of rapid urbanization elsewhere in the country.
\end{abstract}

Keywords: Image classification, Land use/cover, Remote sensing, GIS, Change detection

DOI: $10.7176 / \mathrm{JEES} / 11-16-02$

Publication date:June $30^{\text {th }} 2021$

\section{Introduction}

\subsection{Back ground}

Urbanization is the spatial concentration of people and economic activity. It can also be defined as the transformation of rural society into an urban society as a result of socio-economic and political growth leading to formation and expansion of urban agglomerations and city centres along with changing land use patterns. As cities are growing, the demand for resources like water, land etc. has grown proportionally to the growing rate of the urban population. This causes cities to be experiencing increasing signs of environmental stress, notably in the form of poor air quality, excessive noise and traffic congestion (Tirziu, 2020). The loss of this natural vegetation has great implications such as destruction of wildlife habitat, depreciation or outright wiping off of genetic pools, loss of food and medicinal herbs, promotion of desertification and drought among others and the building up of greenhouse gasses. Satellite image data provides the potential to obtain land cover information from inaccessible locations at more frequent intervals and also more economical than those obtained by traditional methods (Martin \& Howarth, 1989; Trotter, 1991; Treitz, Howarth \& Gong, 1992). The advantages of satellite imagery as compared to aerial photography include regular repeat coverage, recovering data from the same area at the same time of the day, consistence scale and look-angle, and lower cost (Kressler \& Steinnocher, 1996).Planners and designers therefore need efficient tools to quantitatively evaluate and compare the impact of alternative plans and designs so that more informed development Vegetation cover plays an important role in the wellbeing of humans. The study recognizes that urbanization often is inevitable and parts of the process are irreversible.

As the urban population increases, more buildings, services and infrastructure are needed. However, in most developing countries, vegetation spaces and structures are disappearing quickly at the expense of physical and population densification and poor planning. As a result, the vegetation is posed with the challenge of degradation and its eventual loss. The study seeks to analyses the urban expansion as compared to the rate of vegetation loss looking at Jimma town. Jimma Town in 1990 had a population of 2,486,155, persons as compared to 1,593,823 people in the year 2000. Thus, Jimma town recorded the highest percentage increase in population i.e. (38.1\%) over the 30-years period (CSA, 2014). This implies that about 892,332 people have been added to the region 
indicating a probable widening of the existing residential, educational and commercial areas. The expansion of these sectors cannot be done without the clearing of vegetated grounds leading to the loss of vegetation. In using GIS analysis and Remote sensing techniques, future predictions and trends of the urban land use and land cover and its subsequent development could be modelled and their results could help city planners and policy makers attain and sustain future urban development.

\subsection{Objectives of the study}

This project is aimed at Investigating the extent of vegetation loss through urban expansion in and around Jimma Town over a 30 period of 6 years interval by using Geographic Information System (GIS) and Remote Sensing (RS) techniques.

\subsection{Specific objectives}

$\checkmark \quad$ To identify the various lands use and land cover (LULC) classes within and around Jimma town and their spatio-temporal distribution.

$\checkmark \quad$ To identify the association between urban expansion and vegetation loss.

\subsection{Research questions}

i. What are the various land use and land classes in the study area?

ii. What is the relationship between urban expansion and vegetation loss?

\section{METHODOLOGY}

\subsection{Description of the Project Area}

Jimma town was developed on the Awetu River by the Italian colonial regime in the 1930s. .Jimmaa, is the largest city in southwestern Oromia Region in Ethiopia. It is a special zone of the Oromia Region and is surrounded by Jimma Zone. It has a latitude and longitude of $7^{\circ} 40^{\prime} \mathrm{N} 36^{\circ} 50^{\prime} \mathrm{E}$. Prior to the 2007 census, Jimma was reorganized administratively as a special Zone. Based on the 2007 Census conducted by the Central Statistical Agency of Ethiopia (CSA), this Zone has a total population of 120,960, of whom 60,824 are men and 60,136 women. With an area of 50.52 square kilometers, Jimma has a population density of 2,394.30 all are urban inhabitants. A total of 32,191 households were counted in this Zone, which results in an average of 3.76 persons to a household, and 30,016 housing units. The three largest ethnic groups reported in Jimma were the Oromo $(36.71 \%)$, the Amhara (27.14\%) and the Dawro (10.05\%); all other ethnic groups made up $26.1 \%$ of the population. Amharic was spoken as a first language by $41.58 \%$ and $39.96 \%$ spoke Afan Oromo; the remaining $18.46 \%$ spoke all other primary languages reported. The majority of the inhabitants said they practiced Ethiopian Orthodox Christianity, with $46.84 \%$ of the population reporting they observed this belief, while $39.03 \%$ of the population were Muslim, and $13.06 \%$ were Protestant. The temperature data was collected from Jimma meteorological stations nearby to the Jimma city; the study area has an annual mean temperature ranges from about $12.1 \mathrm{oC}$ to $28 \mathrm{oC}$. The study area receives a mean annual rainfall about 1420 to $1800 \mathrm{~mm}$ (JMS, 2013. Jimma city lies on a low hill on the left side of the wide alluvial plain of the river Gibe and it is crossed by small streams. Topographically it exhibits features of the upper part of the Gibe Omo River basin, made up of gentle slopping 


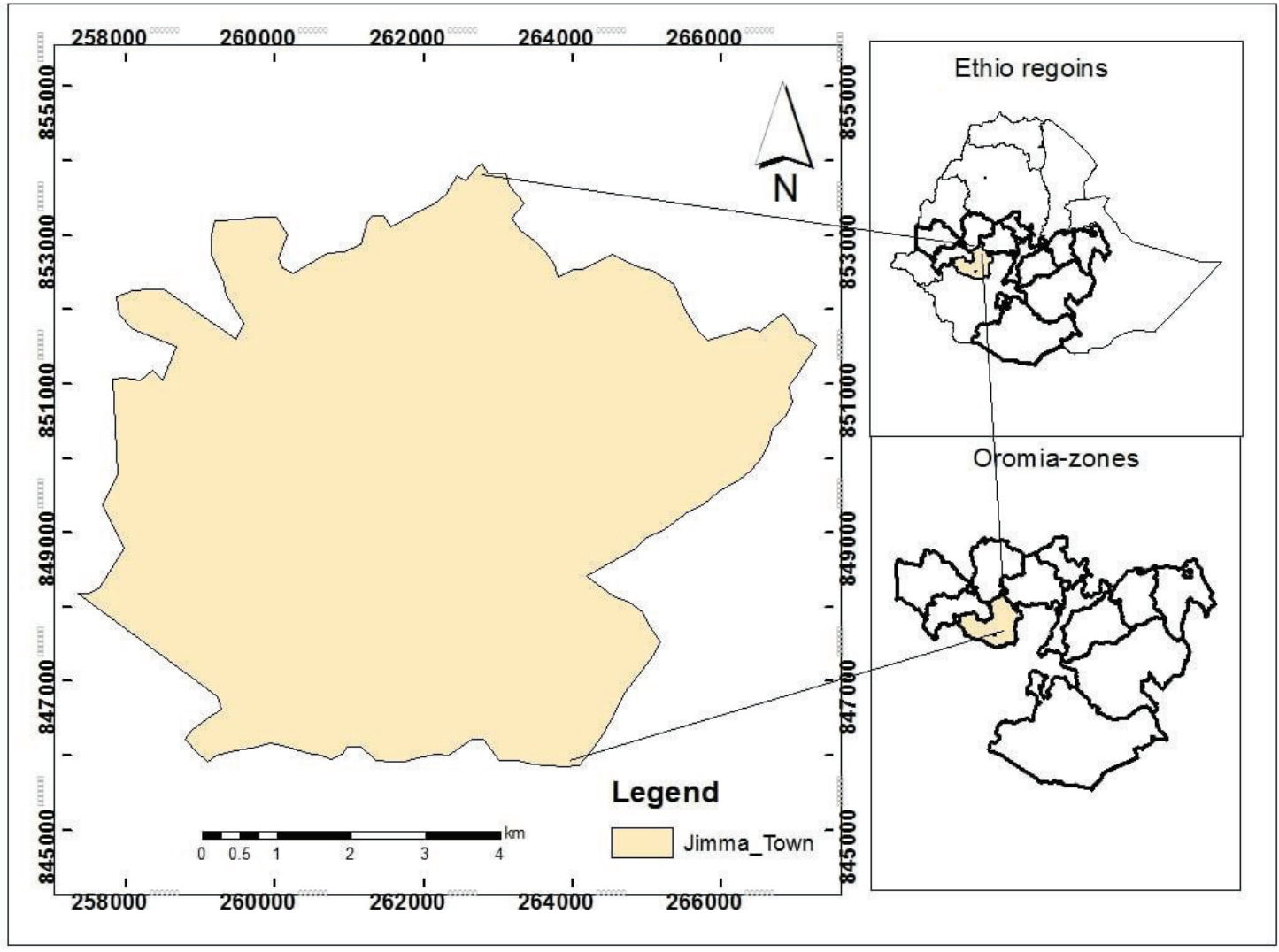

Figure 1:- Map of the study area

Table 1: Description of land use/cover types used in classification

\begin{tabular}{|l|l|l|l|}
\hline LULC Classes & Descriptions & & \\
\hline Built-up area* & $\begin{array}{l}\text { Human-made built surfaces, which include residential and commercial } \\
\text { buildings, other buildings for private and public services, settlement, concert and asphalt } \\
\text { roads. These are predominant land cover in urbanized areas } \\
\text { (cities) }\end{array}$ \\
\hline $\begin{array}{l}\text { Agricultural } \\
\text { land }\end{array}$ & $\begin{array}{l}\text { Areas for growing agricultural crops. The category includes areas } \\
\text { currently under crop, and land under preparation. }\end{array}$ & \\
\hline Wetlands & Marshes, mudflats, swamps & & \\
\hline Grass land & All areas covered with natural grass, woodlots and small shrubs dominated by grass \\
\hline vegetation & Naturally and plantation trees \\
\hline
\end{tabular}

\subsection{Data Processing and Sources of data}

The study employed both remote sensing techniques with GIS as the core components needed for such analysis. In this project work, images of Jimma Town were downloaded via the Landsat remote sensor from the Earth explorer (www.earthexplorer.usgs.gov). The images downloaded were extracted and each layer stacked together using the digital image-processing software ENVI 5.2. The image classification method was adopted for the study. The process requires that images are put in classes and rectified. Supervised classification was employed in classifying the images from 1990, 1996, 2002, 2008, 2014 and 2020 into 5 hierarchical classes; Built up area ,Vegetation, Agricultural land, Grass land, and wetlands based on a modified classification scheme. The maximum likelihood classification algorithm was used in land use classification. Training samples for each image were plotted to ensure that different land use classes could be separated. This classification uses the training data by means of estimating means and variances of the classes, which are used to estimate probabilities and also consider the variability of brightness values in each class (Perumal \& Bhaskaran, 2010). 


\section{Methodology used in the data processing}

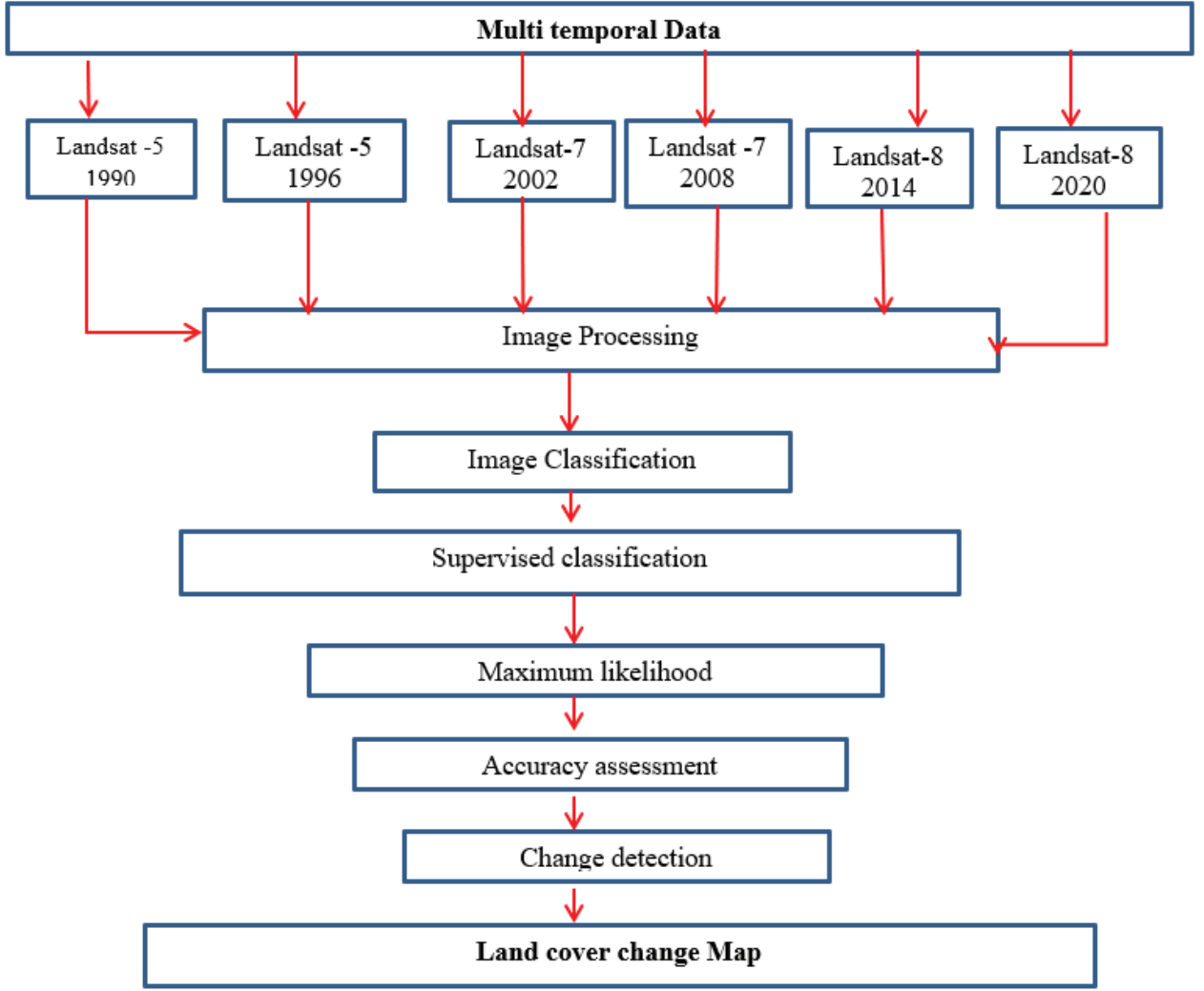

Figure 2: Flow chart of methodology used in the Project work

\section{RESULTS AND DISCUSSION}

The study reveals that there is a remarkable urban expansion in the town especially in the periphery, over the past three decades (1990-2020). The built-up area was dominating the gains while grass land and agricultural land were dominating the losses and suggesting these changes may have been driven by a combination of biophysical, socioeconomic, and policy factors. Rapid urbanization and expansion of settlement may have further triggered the urban ecosystem, mostly gaining massive areas from agricultural land and forest over the past three decades (19902020). The result of the study indicated that there are spatial patterns of major LULC types in the study area (Figure 3). A total of five LULC types were extracted in the study area over the three decade periods. Rapid urban expansion is clearly evident in Figure 3 and shrinking of agricultural land and grassland is also another fundamental LULC change in the study period 1990 and 2020. The overall accuracies for the Land cover map of the study area in the years 1990, 1996, 2002, 2008, 2014 and 2020 were $82.32 \%, 79.51 \%, 83.31 \%, 84.12 \%, 75.21 \%$ and $72.32 \%$ respectively. Producer's accuracy in 1990 land cover map ranged from the lowest value of 53\% to the $86 \%$, while in mapping LULC of year 2020 land cover map ranged from $72 \%$ to $97 \%$. The least classification accuracy was observed for grass land and agricultural land (Table1, 2, 3, 4, 5 and 6) indicate details of accuracy results. 

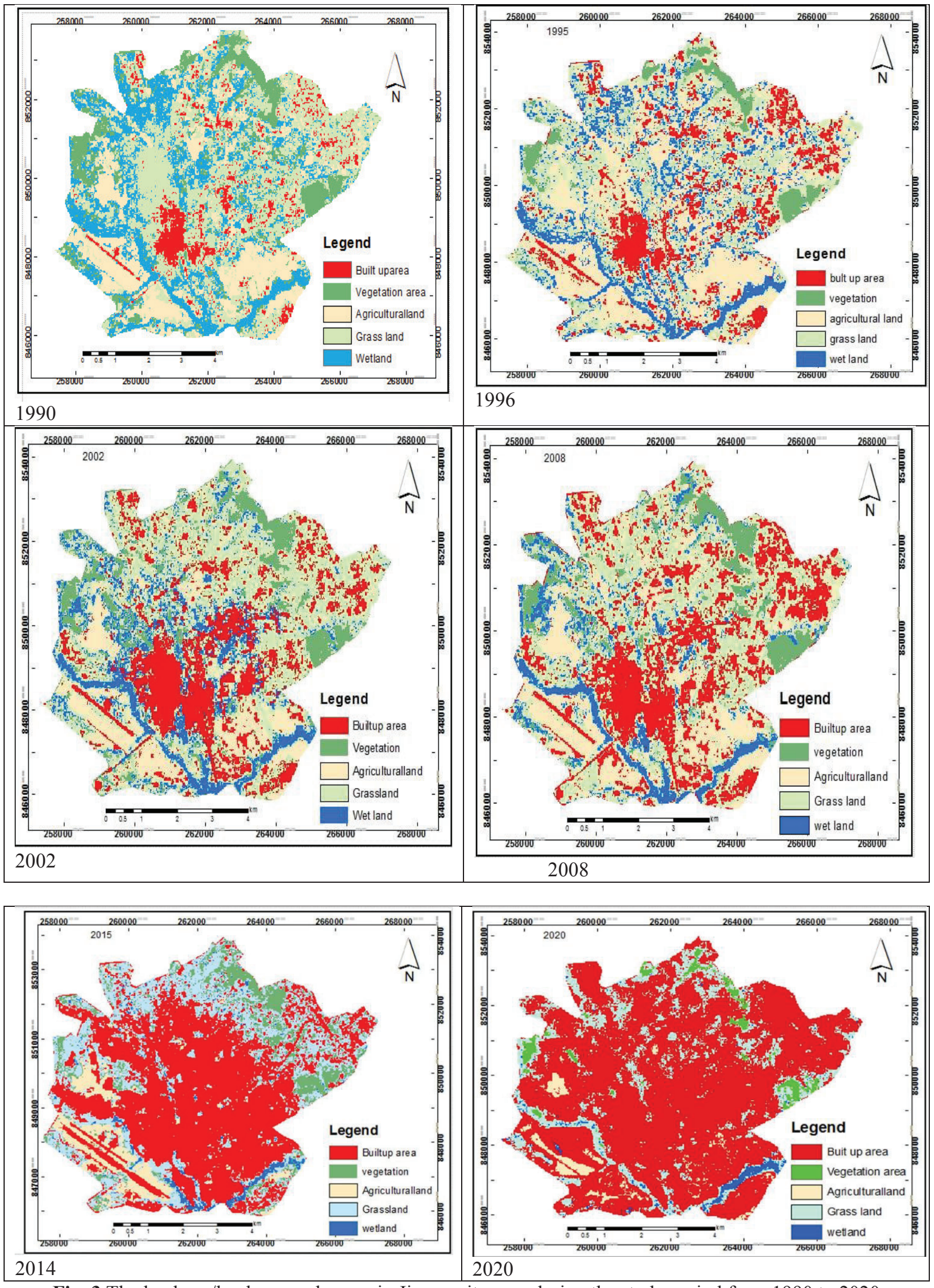

Fig. 3 The land use/land cover changes in Jimma city area during the study period from 1990 to 2020 
Table 1: Overall accuracy assessment in 1990

\begin{tabular}{|c|c|c|c|c|c|c|c|}
\hline \multicolumn{8}{|c|}{ Land cover map of 1990} \\
\hline Built up area & 21 & 12 & 11 & 84.7 & 91.8 & & 0.91 \\
\hline Vegetation area & 15 & 16 & 13 & 83.81 & 84.23 & & 0.83 \\
\hline Agricultural land & 8 & 9 & 5 & 68.71 & 67.45 & $82.32 \%$ & 0.63 \\
\hline Grass land & 9 & 7 & 5 & 53.51 & 56.15 & & 0.57 \\
\hline wet land & 42 & 52 & 46 & 86.71 & 86.12 & & 0.7561 \\
\hline Total & 95 & 96 & 80 & & & & \\
\hline
\end{tabular}

Table 2: Overall accuracy assessment in 1996

\begin{tabular}{|c|c|c|c|c|c|c|c|}
\hline \multicolumn{8}{|c|}{ Land cover map of 1996} \\
\hline Built up area & 13 & 15 & 17 & 84.7 & 91.8 & \multirow{6}{*}{$79.51 \%$} & 0.91 \\
\hline Vegetation area & 17 & 14 & 16 & 83.81 & 84.23 & & 0.83 \\
\hline Agricultural land & 9 & 11 & 9 & 68.71 & 67.45 & & 0.63 \\
\hline Grass land & 7 & 8 & 5 & 53.51 & 56.15 & & 0.57 \\
\hline wet land & 38 & 46 & 37 & 86.71 & 86.12 & & 0.7561 \\
\hline Total & 84 & 94 & 84 & & & & \\
\hline
\end{tabular}

Table 3: Overall accuracy assessment in 2002

\begin{tabular}{|c|c|c|c|c|c|c|c|}
\hline \multicolumn{8}{|c|}{ Land cover map of 2002} \\
\hline Built up area & 16 & 12 & 11 & 84.7 & 91.8 & \multirow{5}{*}{$83.31 \%$} & 0.91 \\
\hline Vegetation area & 19 & 16 & 13 & 83.81 & 84.23 & & 0.83 \\
\hline Agricultural land & 6 & 9 & 5 & 68.71 & 67.45 & & 0.63 \\
\hline Grass land & 11 & 7 & 7 & 53.51 & 56.15 & & 0.57 \\
\hline wet land & 41 & 52 & 46 & 86.71 & 86.12 & & 0.7561 \\
\hline Total & 93 & 96 & 82 & & & & \\
\hline
\end{tabular}

Table 4: Overall accuracy assessment in 2008

\begin{tabular}{|c|c|c|c|c|c|c|c|}
\hline \multicolumn{8}{|c|}{ Land cover map of 2008} \\
\hline Built up area & 17 & 12 & 15 & 84.7 & 91.8 & \multirow{5}{*}{$84.12 \%$} & 0.91 \\
\hline Vegetation area & 15 & 16 & 16 & 83.81 & 84.23 & & 0.83 \\
\hline Agricultural land & 7 & 9 & 7 & 68.71 & 67.45 & & 0.63 \\
\hline Grass land & 10 & 7 & 9 & 53.51 & 56.15 & & 0.57 \\
\hline wet land & 32 & 50 & 43 & 86.71 & 86.12 & & 0.7561 \\
\hline Total & 81 & 94 & 90 & & & & \\
\hline
\end{tabular}

Table 5: Overall accuracy assessment in 2014

\begin{tabular}{llllllll}
\hline \multicolumn{7}{c}{ Land cover map of 2014 } \\
\hline Built up area & 14 & 15 & 15 & 84.7 & 91.8 & 0.91 & 0.83 \\
Vegetation area & 18 & 14 & 11 & 83.81 & 84.23 & $75.21 \%$ & 0.63 \\
Agricultural land & 11 & 11 & 5 & 68.71 & 67.45 & 56.15 & 0.57 \\
Grass land & 7 & 9 & 7 & 53.51 & 86.12 & 0.7561 \\
wet land & 34 & 47 & 47 & & & \\
Total & 84 & 96 & 85 & & & \\
\hline
\end{tabular}


Table 6: Overall accuracy assessment in 2020

\begin{tabular}{|c|c|c|c|c|c|c|c|}
\hline \multicolumn{8}{|c|}{ Land cover map of 2020} \\
\hline Built up area & 17 & 16 & 12 & 84.7 & 91.8 & \multirow{5}{*}{$72.32 \%$} & 0.91 \\
\hline Vegetation area & 16 & 14 & 15 & 83.81 & 84.23 & & 0.83 \\
\hline Agricultural land & 7 & 10 & 7 & 68.71 & 67.45 & & 0.63 \\
\hline Grass land & 9 & 8 & 5 & 53.51 & 56.15 & & 0.57 \\
\hline wet land & 44 & 47 & 48 & 86.71 & 86.12 & & 0.7561 \\
\hline Total & 93 & 95 & 87 & & & & \\
\hline
\end{tabular}

\section{Land use/cover dynamics}

Land use/cover change analysis results and magnitude of land LULC change over the period 1990 and 2020 show that at the early time (1990), grass lands were the dominant land use land cover type, making up 39.03\% of the study area. This was followed by agricultural land (33.20\%), wetland (15.74\%), built-up (13.16\%), vegetation (8.84\%), between years 1990and 2020, the LULC types have shown substantial positive and negative changes (Table 7). Grass land, agricultural land and wetland were the top three LULC types, which have undergone large positive change of $116 \%, 69 \%$ and $66 \%$, respectively. Whereas, vegetation have critically declined during these periods (Table 7).The drastic consequences of ever-increasing demand for residential and institutional building construction spaces, associated poor urban planning(evidenced by widespread informal settlements) are mainly attributable to the observed changes.

This study used past and recent satellite data to evaluate the land use change over the study period. For this purpose, five LULC were formed. These included; built up, vegetation, wetland, grass land and agricultural land. As indicated in Table 7, the highest LULC in 1990 was grassland (39.03\%). This was followed by agricultural land $(33.20 \%)$ and wetland (15.74\%). While built-up (13.16\%) and vegetation (8.84\%) is the least LULC classes in 1990. The analysis of LULCC revealed that the built-up area was $66.89 \mathrm{~km}^{2}(13.16 \%)$ of the study area in 1990 was increased to about $385.83 \mathrm{~km}^{2}$ in 2020 . The agricultural land is decreased from $168.669 \mathrm{~km} 2$ in 1990 to 14.49 $\mathrm{km} 2$ in 2020 whereas, built up areas, the grassland and agricultural land was decreased by the year 2020. There has been a transformation from grassland land and agricultural lands to built-up area caused by rapid urbanization and slum proliferation (Mosammam et al. 2017; Esayas2013; Guan et al. 2011). In 2017, the LULC classification of Jimma city indicates that the highest proportion is vegetation land (30.65\%), followed by barren land $(21.23 \%)$ and open land (17.66\%). The vegetation class shows a radical increasing in the study area because of the protection of the green area as well as the culture of the community in planting edible fruit trees and others. The built-up land cover class shows a remarkable increase between 2002 and 2020, which has been increased in size from $129.2985 \mathrm{~km} 2$ in 2002 to $385.83 \mathrm{~km} 2$ in 2020 , while the agricultural land was experiencing an extremely decreased from $98.973 \mathrm{~km} 2(19.48 \%)$ in 2002 to $14.49 \mathrm{~km}^{2}(2.852536 \%)$ in 2020 .

Table 7: Land use/cover change analysis results magnitude of change over the period 1990 and 2020

\begin{tabular}{|c|c|c|c|c|c|c|c|c|c|c|}
\hline \multirow{2}{*}{\multicolumn{2}{|c|}{ LULC }} & \multicolumn{4}{|c|}{1990} & \multicolumn{3}{|c|}{1996} & \multicolumn{2}{|l|}{2002} \\
\hline & & \multirow{2}{*}{\multicolumn{2}{|c|}{$\begin{array}{l}\text { Area }(\mathrm{km} 2) \\
66.897\end{array}$}} & \multicolumn{2}{|c|}{ Area (\%) } & \multicolumn{2}{|c|}{ Area $(\mathrm{km} 2)$} & Area $(\%)$ & Area $(\mathrm{km} 2)$ & Area $(\%)$ \\
\hline \multicolumn{2}{|c|}{ Built up area } & & & \multicolumn{2}{|l|}{13.16} & \multicolumn{2}{|c|}{127.863} & 25.17142 & 129.2985 & 25.45 \\
\hline \multicolumn{2}{|c|}{ Vegetation area } & \multicolumn{2}{|c|}{44.615} & 8.84 & & & & 7.388246 & 40.068 & 7.88 \\
\hline \multicolumn{2}{|c|}{ Agricultural land } & \multicolumn{2}{|l|}{168.669} & \multicolumn{2}{|l|}{33.20} & & .736 & 20.02799 & 98.973 & 19.48 \\
\hline \multicolumn{2}{|c|}{ Grass land } & \multicolumn{2}{|l|}{198.27} & \multicolumn{2}{|l|}{39.03} & \multicolumn{2}{|c|}{179.541} & 35.34487 & 169.4068 & 30.27 \\
\hline \multicolumn{2}{|c|}{ wet land } & \multicolumn{2}{|l|}{69.518} & \multicolumn{2}{|l|}{15.74} & \multicolumn{2}{|c|}{61.299} & 12.06747 & 45.2385 & 8.90 \\
\hline \multicolumn{2}{|l|}{ Total } & \multicolumn{2}{|l|}{507.969} & \multicolumn{2}{|l|}{100} & \multicolumn{2}{|c|}{507.969} & 100 & 507.9848 & 100 \\
\hline \multicolumn{2}{|c|}{2008} & \multicolumn{3}{|c|}{2014} & \multicolumn{3}{|c|}{2020} & Change (ha) & \multicolumn{2}{|l|}{ change in } \\
\hline $\begin{array}{l}\text { Area } \\
(\mathrm{km} 2)\end{array}$ & $\begin{array}{l}\text { Area } \\
(\%)\end{array}$ & $\begin{array}{l}\text { Area } \\
(\mathrm{km} 2)\end{array}$ & \multicolumn{2}{|c|}{$\begin{array}{l}\text { Area } \\
(\%)\end{array}$} & $\begin{array}{l}\mathrm{Ar} \\
(\mathrm{k} 1\end{array}$ & & $\begin{array}{l}\text { Area } \\
(\%)\end{array}$ & $\begin{array}{l}\text { Area } \\
(\mathrm{km} 2\end{array}$ & \multicolumn{2}{|l|}{$\begin{array}{l}\text { Area } \\
(\%)\end{array}$} \\
\hline 139.966 & 27.55 & 269.77 & \multicolumn{2}{|c|}{53.10735} & & & 75.95542 & +317.4425 & 73 & \\
\hline 45.53 & 8.99 & 46.9002 & 9.1 & & & & 4.349356 & -22.6804 & -14 & \\
\hline 95.736 & 18.03 & 37.453 & 7.3 & 2958 & 14 & & 2.852536 & -154.193 & -41 & \\
\hline 167.44 & 32.96 & 142.03 & 27. & 5975 & & & 17.2481 & -110.655 & -36 & \\
\hline 41.299 & 7.47 & 10.82 & 2.1 & 0477 & 8.1 & & 1.594585 & -61.4175 & -23 & \\
\hline 507.97 & 100 & 507.98 & 100 & & & & 100 & & & \\
\hline
\end{tabular}

+ and - signs, respectively, denote increase and decrease in LULC areas

The increment of built up area over the study period was associated with rapid population growth, migration 
of people from neighboring city and unable to compete the land lease price. These results are collaborate with (te Lintelo et al. 2018 and Mosammam et al. 2017) who reported that the rapid urban population is a key challenge of the twenty-first century. From land cover classes namely built up shows an increasing trend throughout the study periods (Fig. 3). The built-up area shows increasing trend from 1990 to 2002 covering an area of $66.897 \mathrm{~km}^{2}$ $(13.16 \%)$ in the year 1990 and $129.2985 \mathrm{~km}^{2}(25.45 \%)$ in the year 2002 and eight years later this land cover class increased to $385.83 \mathrm{~km}^{2}(75.95542 \%)$ in the year 2020 . The trends of agricultural land, grassland, and vegetation were decreased throughout the study periods except for the former class in 2002 but the rate of decrease was different. The former class expanded to forest area following rapid urban expansion near to town center on croplands in 2002. However, a built-up area rapidly replaced agricultural land following massive constructions, This finding is in line with Asmat and Zamzami(2012) and Esayas (2013) which explain about increased built-up area due to rapid, unstructured and unplanned development. Extreme decline of grassland and agricultural land was occurred in the year 2002 to 2020. This declining trend of the land is due to increasing land requirements for house construction, which is arising from rapid population growth and uncontrolled response by the government (Lejano and Bianco 2018), which enhances the problem of informal house constructions. These findings are supported by Roberts and Okanya (2018), who reported urban informality, is the outcome of either housing deficit or unaffordable cost of formal house rent. It is observed that the vegetation cover has increased from $40.068 \mathrm{~km}^{2}$ $(7.88 \%)$ in the year 2002 to $47.9002 \mathrm{~km}^{2}(9.4294 \%)$ in the year 2015 . On the other hand, the wetland of the study area shows a decreasing trend from 1990 to 2020 covering a total area of $69.518 \mathrm{~km}^{2}(15.74 \%)$ in the year 1990 and $8.1 \mathrm{~km}^{2}(1.594585 \%)$ in 2020. Maximum positive change is observed in built-up area cover, during 20022020, whereas maximum negative change is observed in grass land and agricultural land during the year20082020 .

\section{CONCLUSION}

This study provided spatially explicit information about LULC dynamics that Jimma and its surrounding has undergone during the past three decades. The result of the study has revealed that, the rapid expansion of Jimma city coupled with fast demographic change and high demand for urban land has resulted in drastic changes in key ecosystems including natural forest, grasslands and wetlands. This imply that research and policy institutions need to give due attention to the dynamics and long-term socio-ecological impacts. This suggests that critical holistic scientific and development measures towards environmental sustainability in and around Jimma city need to be taken by both science and the policy environments. In sum, the results could contribute to informed decision making processes towards environmental sustainability in rapidly urbanizing areas of the country. Increasing urbanization and rapid population growth has exaggerated the problem of informal settlements. An informal settlement in the urban periphery is a common and serious problem in Ethiopia particularly in Jimma city. Due to informal settlement, the scarce land resource is misused and the government lost revenue from the illegal dwellers. The government is facing great challenges from the emerging informal settlements as they accommodate a substantial proportion of the urban population who lives in substandard living conditions. Understanding the characteristics, extent and pattern of land use change are an important supporting tool for decision-making processes. This paper was analyzed the LULCC to identify the extent of informal settlements using GIS and remote sensing technologies over the time period of 30 years. Combing data from socioeconomic survey and multitemporal remote sensing images reveals that there is a fast increase of informal settlements outside of city municipality boundaries. The LULCC analysis results indicated that the built-up area has shown an increasing trend over the last two decades, i.e., the built-up land use type is the only land use class that shows increasing trends in the study area, while agricultural land use was affected largely due to conversion into built-up areas. The rapid increasing of built-up areas and a fast declining of agricultural lands leads to dramatic changes in LULC classes in the study area.

\section{REFERENCE}

Asmat, A., \& Zamzami, S. Z. (2012). Automated house detection and delineation using optical remote sensing technology for informal human settlement. Procedia-Social and Behavioral Sciences, 36, 650-658.

Bodo, T. (2019). Rapid urbanisation: theories, causes, consequences and coping strategies. Annals of Geographical Studies, 2(3), 32-45.

Charruau, P., Cedeno-Vázquez, J. R., \& Köhler, G. (2015). Amphibians and reptiles. In Biodiversity and conservation of the Yucatán Peninsula (pp. 257-293). Springer, Cham.

Kressler, F., \& Steinnocher, K. (1996). Change detection in urban areas using satellite images and spectral mixture analysis. International Archives of Photogrammetry and Remote Sensing, 31, 379-383.

Kumar, S., Yadava, R. N., Singh, S. K., \& Mustak, S. (2014). Assessment of Land Use around highly populous business centre of Lucknow City using GIS techniques and high resolution Google Earth's Quickbird satellite data. Bulletin of Environmental and Scientific Research, 3(1), 8-14.

Lejano, R. P., \& Del Bianco, C. (2018). The logic of informality: Pattern and process in a São Paulo 
favela. Geoforum, 91, 195-205.

Mosammam, H. M., Nia, J. T., Khani, H., Teymouri, A., \& Kazemi, M. (2017). Monitoring land use change and measuring urban sprawl based on its spatial forms: The case of Qom city. The Egyptian Journal of Remote Sensing and Space Science, 20(1), 103-116.

Roberts, R. E., \& Okanya, O. (2020). Measuring the socio-economic impact of forced evictions and illegal demolition; A comparative study between displaced and existing informal settlements. The Social Science Journal, 1-20.

te Lintelo, D., Lakshman, R., Mansour, W., Soye, E., Ficcarelli, T., \& Woodward, W. (2018). Wellbeing and protracted urban displacement: Refugees and hosts in Jordan and Lebanon.

Tîrziu, A. M. (2020). Urbanization and cities of the future. International Journal for Innovation Education and Research, 8(3). 